\title{
Inhibitory control by one stimulus after an increase in the frequency of reinforcement associated with another stimulus
}

\author{
RALPH W. RICHARDS \\ Colorado State University, Fort Collins, Colorado 80523
}

\begin{abstract}
Pigeons were trained on a multiple variable-interval 5-min variable-interval 5-min schedule and then shifted to either a multiple variable-interval 1-min variable-interval 5-min or a multiple variable-interval 30-sec variable-interval 5-min schedule. A generalization test was subsequently administered along the dimension containing the stimulus associated with the variable-interval 5-min component. The generalization gradients for subjects that received multiple variable-interval 1 -min variable-interval 5-min training were not consistent in shape. However, an incremental gradient was obtained from each subject that received multiple variable-interval 30 -sec variable-interval 5 -min training. Thus, a sufficiently large reduction in merely the relative frequency of reinforcement during a stimulus resulted in that stimulus' acquiring inhibitory control over responding.
\end{abstract}

Incremental generalization gradients have been obtained around the stimulus associated with the second component (S2) of various two-component multiple schedules. For example, incremental gradients have been obtained when S2 was associated with extinction (EXT; Honig, Boneau, Burstein, \& Pennypacker, 1963) and when S2 was associated with a schedule involving a lower frequency of reinforcement than S1 (Weisman, 1969) and with a longer delay of reinforcement than S1 (Richards, 1973, 1974; Richards \& Hittesdorf, 1976; Richards \& Marcattilio, 1978). In these studies, the stimuli associated with the component schedules presumably were selected from orthogonal stimulus dimensions (with orthogonal stimulus dimensions, all stimuli on one dimension are equally distant from all stimuli on the other dimension), and the generalization test was conducted along the dimension containing S2. To the extent that incremental gradients are indicative of inhibitory stimulus control (as suggested by Jenkins, 1965; Rilling, 1977; Terrace, 1972), the aforementioned studies indicate that a stimulus associated with either extinction or a schedule of food reinforcement may exert inhibitory control over responding.

Weisman (1969) suggested that a subject's prior reinforcement history is an important factor in determining whether a stimulus associated with a schedule of food reinforcement comes to have

Reprints may be obtained from the author, Department of Psychology, Colorado State University, Fort Collins, Colorado 80523. The author is grateful to A.J. Marcattilio for his help in collecting the present data. The apparent absence of negative behavioral contrast is not discussed because a control group was not run to assess the effects of extended training. inhibitory control over responding. Weisman found that only one of four pigeons that were switched from multiple VI (variable-interval) 5-min VI 5-min to a multiple VI 1-min VI 5-min schedule showed an incremental gradient around $S 2$, but all four pigeons switched from a multiple VI 1-min VI 1-min to a multiple VI 1-min VI 5-min schedule showed an incremental gradient around S2. That is, whether or not an incremental gradient was obtained depended on the prior history of the subject. Weisman concluded that merely reducing the relative frequency of S2 reinforcement [frequency of S2 reinforcement $\div$ (frequency of $\mathrm{S} 1$ reinforcement + frequency of $S 2$ reinforcement)] to less than 0.5 by increasing the absolute frequency of S1 reinforcement was not sufficient to convert S2 into an inhibitory stimulus. Rather, a reduction in the absolute frequency of S2 reinforcement was also required.

However, a recent study by Richards and Marcattilio (1978), in which S2 was associated with a delay of reinforcement and S1 was not, suggested that prior reinforcement history might not be important if sufficient training is provided on the terminal multiple schedule. In Experiment 2, Richards and Marcattilio (1978) consistently obtained incremental gradients after subjects were exposed to a multiple EXT VI 1 -min (delay) $\rightarrow$ multiple VI 1 -min VI 1-min (delay) sequence, even though the absolute conditions of reinforcement during $S 2$ were not altered. It also was suggested that Weisman's failure to obtain incremental gradients from subjects trained on the multiple VI 5-min VI 5-min $\rightarrow$ multiple VI 1 -min VI 5-min sequence might have been due to the short duration of training $(392 \mathrm{~min})$ that he provided 
on the multiple VI 1-min VI 5-min schedule. But, since schedules involving delayed reinforcement and low frequencies of reinforcement may operate differently in producing incremental gradients, it seemed worthwhile to examine the reliability of Weisman's findings. There were two basic differences between the present study and Weisman's study. First, the present study provided more training on the terminal multiple schedule $(840 \mathrm{~min})$. Second, two magnitudes of reduction in the relative frequency of S2 reinforcement were examined. One group of subjects was exposed to a multiple VI 5 -min VI 5-min $\rightarrow$ multiple VI 1-min VI 5-min sequence, and another group was exposed to a multiple VI 5-min VI 5-min $\rightarrow$ multiple VI 30-sec VI 5-min sequence. This second sequence was included because it seemed possible that the magnitude by which Weisman reduced the relative frequency of S2 reinforcement might have been too small to consistently produce incremental gradients.

\section{METHOD}

\section{Subjects}

Twelve adult White Carneaux pigeons were maintained at approximately $75 \%$ of their free-feeding weights. All birds previously had been trained to eat from a food magazine, and several of the birds had been partly trained to peck the all-white center key in the chamber described below. Two other subjects were discarded, one because of an apparatus failure and another because of illness.

\section{Apparatus}

The experimental chamber (internal dimensions of $37 \times 32.5$ $\times 33 \mathrm{~cm}$ ) was constructed entirely of plywood except for the metal intelligence panel and a Plexiglas window on a side wall. The center key $(3.5 \mathrm{~cm}$ in diameter $)$ on the intelligence panel required a force of approximately $.15 \mathrm{~N}$ to operate and also was used as a projection screen for the Kodak Carousel projector. The two training stimuli, S1 and S2, were, respectively, a homogeneous white circle $(2.5 \mathrm{~cm}$ in diameter) and a black vertical line $(2.5 \mathrm{~cm}$ long and approximately $2 \mathrm{~mm}$ thick) on the white surround. The seven generalization test stimuli were S1, S2, a horizontal black line on a white surround, and black lines on a white surround inclined at $\pm 30^{\circ}$ and $\pm 60^{\circ}$ from vertical. The center of this key (and the two covered side keys) was $8 \mathrm{~cm}$ above the wire-mesh floor. The lower edge of the $6 \times 5 \mathrm{~cm}$ feeder opening was approximately $3 \mathrm{~cm}$ above the floor. Three CM 1820 bulbs also were mounted on the intelligence panel, $5.5 \mathrm{~cm}$ above each key, and served as houselights. Standard electromechanical equipment was located in another room.

\section{Procedure}

Much of the training and testing procedure was identical to that described by Weisman (1969). Subjects were first trained to peck at $\mathrm{Sl}$ and then received an additional session of continuous reinforcement for pecks at $\mathbf{S 2}$. In all subsequent training sessions, either S1 or S2 was presented on the key for $1 \mathrm{~min}$, and successive presentations of these stimuli were separated by a 10 -sec blackout. Responding during the blackout had no scheduled consequences. During the next three sessions ( 50 reinforcements per session), S1 and S2 alternated each minute, and the response requirement was gradually increased until a fixed-ratio 45 schedule was attained. The keylight was always extinguished when the reinforcer, 3-sec access to mixed grain, was presented.

All subjects then received 2 sessions of multiple VI $30-\mathrm{sec}$ VI 30-sec, 3 sessions of multiple VI 1-min VI 1-min, 3 sessions of multiple VI 3-min VI 3-min, and 20 sessions of multiple VI 5-min VI 5-min training. Half of the subjects then received 30 sessions of training on a multiple VI 1-min VI 5-min schedule, and the other half received 30 sessions of training on a multiple VI 30-sec VI 5-min schedule. Each of these sessions contained 14 presentations of S1 and 14 presentations of S2. The order of stimulus presentations was mixed. Available reinforcements that were not collected during one stimulus presentation carried over to the next presentation of that stimulus.

The next session began with a brief period of additional training (14 stimulus presentations) and ended with a generalizaton test. During the generalization test, each of the seven test stimuli was presented once in each of 10 blocks. In this session, the stimuli were presented for $30 \mathrm{sec}$, and successive stimuli were separated by a 5 -sec blackout. No reinforcement was delivered during the generalization test.

\section{RESULTS}

Table 1 shows the $\mathrm{S} 1$ and $\mathrm{S} 2$ response rates for individual birds that received the multiple VI 5-min VI 5 -min $\rightarrow$ multiple VI 1-min VI 5-min sequence. All birds, except B-3056, showed nearly equivalent response rates to $\mathrm{S} 1$ and $\mathrm{S} 2$ at the end of multiple VI 5-min VI 5-min training. After the multiple VI 1-min VI 5-min schedule was introduced, all birds,

Table 1

Mean Responses per Minute in Blocks of Five Sessions During the Last 10 Sessions of Multiple VI 5-min VI 5-min Training and During All Sessions of Multiple VI 1-min VI 5-min Training

\begin{tabular}{|c|c|c|c|c|c|c|c|c|c|}
\hline \multirow[b]{2}{*}{ B-5044 } & \multicolumn{3}{|c|}{ VI 5-min VI 5-min } & \multicolumn{6}{|c|}{ VI 1-min VI 5-min } \\
\hline & $\begin{array}{l}\text { S1 } \\
\text { S2 }\end{array}$ & $\begin{array}{l}25.5 \\
28.2\end{array}$ & $\begin{array}{l}24.3 \\
27.4\end{array}$ & $\begin{array}{l}41.2 \\
40.9\end{array}$ & $\begin{array}{l}54.7 \\
38.4\end{array}$ & $\begin{array}{l}73.2 \\
38.7\end{array}$ & $\begin{array}{l}94.6 \\
50.6\end{array}$ & $\begin{array}{l}91.3 \\
51.8\end{array}$ & $\begin{array}{l}80.3 \\
40.2\end{array}$ \\
\hline B-1074 & $\begin{array}{l}\text { S1 } \\
\text { S2 }\end{array}$ & $\begin{array}{l}27.4 \\
27.9\end{array}$ & $\begin{array}{l}33.3 \\
33.3\end{array}$ & $\begin{array}{l}50.7 \\
47.4\end{array}$ & $\begin{array}{l}81.7 \\
59.7\end{array}$ & $\begin{array}{l}94.2 \\
63.0\end{array}$ & $\begin{array}{l}89.1 \\
52.6\end{array}$ & $\begin{array}{l}84.3 \\
65.1\end{array}$ & $\begin{array}{l}93.5 \\
63.3\end{array}$ \\
\hline B-1035 & $\begin{array}{l}\text { S1 } \\
\text { S2 }\end{array}$ & $\begin{array}{l}7.3 \\
5.9\end{array}$ & $\begin{array}{l}9.0 \\
7.7\end{array}$ & $\begin{array}{l}31.5 \\
28.9\end{array}$ & $\begin{array}{l}41.6 \\
30.9\end{array}$ & $\begin{array}{l}41.7 \\
22.7\end{array}$ & $\begin{array}{l}42.8 \\
19.1\end{array}$ & $\begin{array}{l}46.3 \\
21.6\end{array}$ & $\begin{array}{l}50.2 \\
22.1\end{array}$ \\
\hline B-3056 & $\begin{array}{l}\text { S1 } \\
\text { S2 }\end{array}$ & $\begin{array}{l}35.4 \\
41.2\end{array}$ & $\begin{array}{l}31.6 \\
37.1\end{array}$ & $\begin{array}{l}40.7 \\
39.7\end{array}$ & $\begin{array}{l}61.9 \\
50.7\end{array}$ & $\begin{array}{l}85.5 \\
56.7\end{array}$ & $\begin{array}{l}75.8 \\
51.4\end{array}$ & $\begin{array}{l}86.0 \\
59.3\end{array}$ & $\begin{array}{l}82.8 \\
62.3\end{array}$ \\
\hline B-5920 & $\begin{array}{l}\text { S1 } \\
\text { S2 }\end{array}$ & $\begin{array}{l}37.8 \\
40.2\end{array}$ & $\begin{array}{l}51.2 \\
51.9\end{array}$ & $\begin{array}{l}69.7 \\
56.6\end{array}$ & $\begin{array}{l}61.4 \\
48.0\end{array}$ & $\begin{array}{l}55.9 \\
47.8\end{array}$ & $\begin{array}{l}56.0 \\
51.4\end{array}$ & $\begin{array}{l}54.8 \\
48.6\end{array}$ & $\begin{array}{l}38.6 \\
37.1\end{array}$ \\
\hline B-652 & $\begin{array}{l}\text { S1 } \\
\text { S2 }\end{array}$ & $\begin{array}{l}20.2 \\
17.5\end{array}$ & $\begin{array}{l}20.9 \\
20.4\end{array}$ & $\begin{array}{l}30.9 \\
28.2\end{array}$ & $\begin{array}{l}42.0 \\
32.7\end{array}$ & $\begin{array}{l}48.9 \\
39.3\end{array}$ & $\begin{array}{l}55.9 \\
38.4\end{array}$ & $\begin{array}{l}60.6 \\
43.7\end{array}$ & $\begin{array}{l}79.3 \\
49.7\end{array}$ \\
\hline
\end{tabular}




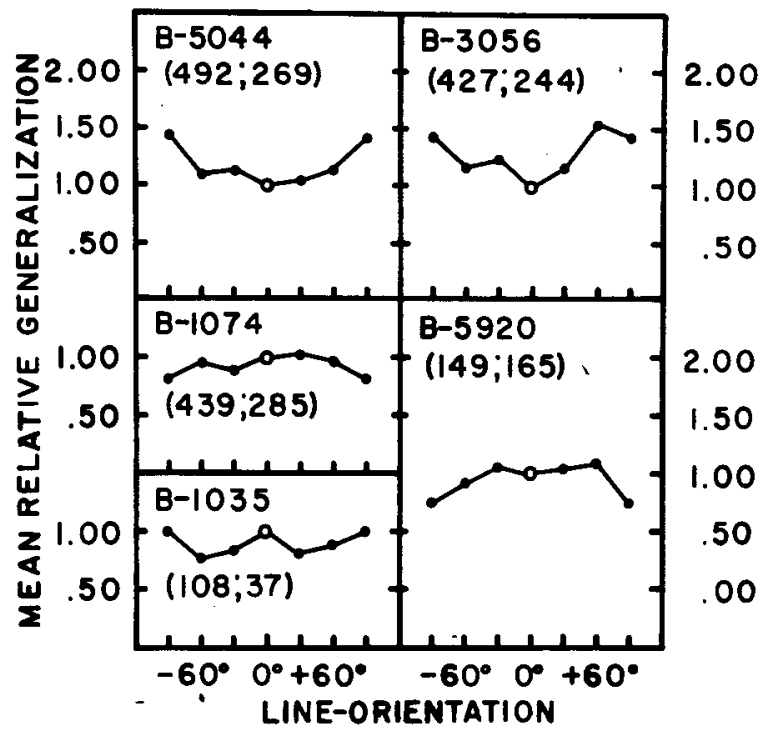

Figure 1. The relative geacanliontion gradients for subjects exposed to the multiple VI 5-min VI 5-min $\rightarrow$ multiple VI 1-min VI 5-min sequence. The dependent raible is the number of responses to the test stimulus divided by the number of responses to $\mathbf{S 2}$ during the generalization test. The numbers in parentheses near each gradient are, in order, the number of responses to S1 and S2 during the generalization test. For the sake of symmetry, the amount of relative generalization to the horizontal line has been plotted at both $+90^{\circ}$ and $-90^{\circ}$ for each subject.

except B-5920, consistently responded faster during S1 than during S2. Changing the multiple schedule produced an increase in both S1 and S2 responding (i.e., positive induction occurred), but the magnitude of the increase was greater for $\mathrm{S} 1$ responding. Figure 1 shows the relative generalization gradients for each bird, except B-652, which ceased responding early in the generalization test. The dependent variable in this figure is the number of responses to the test stimulus divided by the number of responses to $\mathrm{S} 2$ during the generalization test; the numbers in parentheses near each gradient are, in order, the total number of responses to S1 and S2 during the generalization test. There was no con- sistency in the shape of these gradients. The gradients for B-5044 and B-3056 were U shaped and had their nadirs located at S2, but the gradients for the other three birds were either irregular or shaped like an inverted $\mathrm{U}$. Absolute gradients were similar in shape to relative gradients.

Table 2 and Figure 2 show the response rates and the generalization gradients for birds exposed to the multiple VI 5-min VI 5-min $\rightarrow$ multiple VI 30-sec VI 5-min sequence. None of these birds showed differential responding to S1 and S2 during multiple VI 5-min VI 5-min training, but all birds responded much faster to S1 than to S2 after the multiple VI 30-sec VI 5-min schedule was introduced. Changing the multiple schedule generally increased response rates to both stimuli (i.e., positive induction again occurred), although for some subjects, the S2 increase seemed to be temporary. The relative (and absolute) generalization gradient for each subject was U shaped and its nadir was located at or near S2.

\section{DISCUSSION}

The present study's failure to obtain incremental gradients consistently after the multiple VI 5-min VI 5-min $\rightarrow$ multiple VI 1-min VI 5-min sequence replicates Weisman's (1969) finding and shows that his results probably were not due to insufficient training as suggested by Richards and Marcatillio (1978). However, the consistency with which incremental gradients were obtained after the multiple VI 5-min VI 5-min $\rightarrow$ multiple VI 30-sec VI 5-min sequence shows that Weisman's conclusions have, at best limited generality. Evidently, Weisman's results were due to his not reducing the relative frequency of $S 2$ reinforcement enough. In the present study, when the relative frequency of $\mathrm{S} 2$ reinforcement was changed from .50 to .09 by increasing the frequency of $S 1$ reinforcement, an incremental gradient was obtained from every bird. Moreover, a recent study by Couch (1975, Experiment 1)

Table 2

Mean Responses per Minute in Blocks of Five Sessions During the Last 10 Sessions of Multiple VI 5-min VI 5-min Training and During All Sessions of Multiple VI 30-sec VI 5-min Training

\begin{tabular}{|c|c|c|c|c|c|c|c|c|c|}
\hline \multirow[b]{2}{*}{ B-2434 } & \multicolumn{4}{|c|}{ VI 5-min VI 5-min } & \multicolumn{4}{|c|}{ VI 30-sec VI 5-min } & \multirow[b]{2}{*}{$\begin{array}{l}64.6 \\
31.1\end{array}$} \\
\hline & $\begin{array}{l}\text { S1 } \\
\text { S2 }\end{array}$ & $\begin{array}{l}28.4 \\
30.3\end{array}$ & $\begin{array}{l}31.0 \\
29.8\end{array}$ & $\begin{array}{l}45.5 \\
38.0\end{array}$ & $\begin{array}{l}62.4 \\
40.5\end{array}$ & $\begin{array}{l}70.4 \\
37.5\end{array}$ & $\begin{array}{l}61.8 \\
29.7\end{array}$ & $\begin{array}{l}64.9 \\
31.7\end{array}$ & \\
\hline B- 2572 & $\begin{array}{l}\text { S1 } \\
\text { S2 }\end{array}$ & $\begin{array}{l}8.0 \\
7.7\end{array}$ & $\begin{array}{r}9.3 \\
10.4\end{array}$ & $\begin{array}{l}40.3 \\
36.4\end{array}$ & $\begin{array}{l}56.0 \\
35.6\end{array}$ & $\begin{array}{l}77.7 \\
26.1\end{array}$ & $\begin{array}{l}74.6 \\
19.3\end{array}$ & $\begin{array}{l}64.2 \\
24.0\end{array}$ & $\begin{array}{l}63.7 \\
14.1\end{array}$ \\
\hline B-970 & $\begin{array}{l}\text { S1 } \\
\text { S2 }\end{array}$ & $\begin{array}{l}16.4 \\
19.1\end{array}$ & $\begin{array}{l}23.1 \\
24.6\end{array}$ & $\begin{array}{l}78.7 \\
58.9\end{array}$ & $\begin{array}{l}87.2 \\
46.9\end{array}$ & $\begin{array}{l}71.8 \\
32.0\end{array}$ & $\begin{array}{l}80.5 \\
35.1\end{array}$ & $\begin{array}{l}85.2 \\
30.7\end{array}$ & $\begin{array}{l}84.7 \\
33.3\end{array}$ \\
\hline B-2762 & $\begin{array}{l}\text { S1 } \\
\text { S2 }\end{array}$ & $\begin{array}{l}31.9 \\
33.0\end{array}$ & $\begin{array}{l}36.0 \\
36.9\end{array}$ & $\begin{array}{l}58.0 \\
39.5\end{array}$ & $\begin{array}{l}63.9 \\
31.9\end{array}$ & $\begin{array}{l}72.3 \\
31.8\end{array}$ & $\begin{array}{l}76.6 \\
34.5\end{array}$ & $\begin{array}{l}72.8 \\
36.8\end{array}$ & $\begin{array}{l}76.7 \\
37.1\end{array}$ \\
\hline B-5939 & $\begin{array}{l}\text { S1 } \\
\text { S2 }\end{array}$ & $\begin{array}{l}7.8 \\
8.7\end{array}$ & $\begin{array}{l}7.0 \\
5.7\end{array}$ & $\begin{array}{l}27.5 \\
18.2\end{array}$ & $\begin{array}{l}73.7 \\
34.0\end{array}$ & $\begin{array}{l}78.9 \\
17.2\end{array}$ & $\begin{array}{l}90.8 \\
34.1\end{array}$ & $\begin{array}{l}93.9 \\
26.3\end{array}$ & $\begin{array}{l}91.0 \\
22.2\end{array}$ \\
\hline B-438 & $\begin{array}{l}\text { S1 } \\
\text { S2 }\end{array}$ & $\begin{array}{l}22.0 \\
22.5\end{array}$ & $\begin{array}{l}16.6 \\
16.7\end{array}$ & $\begin{array}{l}42.1 \\
31.9\end{array}$ & $\begin{array}{l}49.5 \\
34.1\end{array}$ & $\begin{array}{l}46.5 \\
27.5\end{array}$ & $\begin{array}{l}48.1 \\
17.1\end{array}$ & $\begin{array}{l}52.0 \\
20.2\end{array}$ & $\begin{array}{l}57.0 \\
13.5\end{array}$ \\
\hline
\end{tabular}




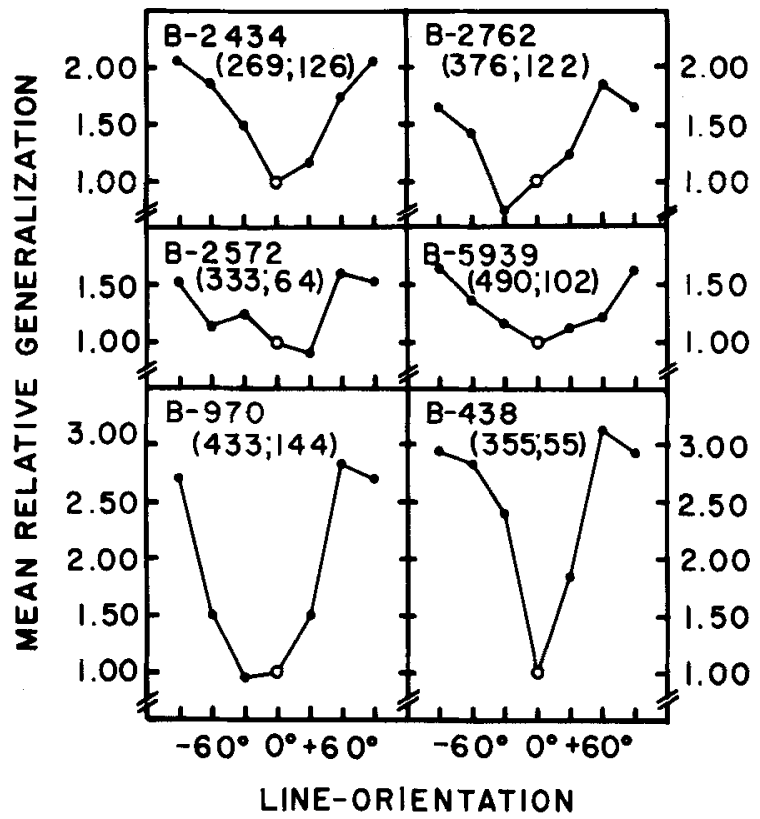

Figure 2. The relative generalization gradients for subjects exposed to the multiple VI 5-min VI 5-min $\rightarrow$ multiple VI 30-sec VI 5-min sequence. The dependent variable is the number of responses to the test stimulus divided by the number of responses to $\mathbf{S 2}$ during the generalization test. The numbers in parentheses near each gradient are, in order, the number of responses to S1 and S2 during the generalization test. For the sake of symmetry, the amount of relative generalization to the horizontal line has been plotted at both $+90^{\circ}$ and $-90^{\circ}$ for each subject.

suggests that the relative frequency of $\mathrm{S} 2$ reinforcement in a multiple VI 1 -min VI 5 -min schedule is not sufficiently low to reliably produce an incremental gradient, even if subjects are pretrained on a multiple VI 1-min VI 1-min schedule. Even though Couch employed procedures nearly identical to those of Weisman, he obtained a decremental gradient around S2. Overall, then, it seems that the context in which a schedule currently appears is more important than contexts in which it previously appeared.

To the extent that an incremental gradient is indicative of inhibition, the present study shows that a stimulus may acquire inhibitory control following a reduction in merely the relative frequency of reinforcement associated with responding during that stimulus. While most researchers (e.g., Jenkins, 1965; Richards, 1973, 1974; Richards \& Hittesdorf, 1976; Richards \& Marcattillio, 1978; Rilling, 1977; Terrace, 1972; Weisman, 1969, 1970; Weisman \& Ramsden, 1973; Yarczower, 1970) have employed such gradients as their measure of inhibition, Hearst, Besley, and Farthing (1970) raised the theoretical possibility that the various line orientations might not be equally similar to the blank key (i.e., that the orthogonality assumption might not be warranted): if birds look at the key only near where the "training" line appears, the "test" lines may look more like a blank key because that portion of the key is blank. This interpretation suggests, unless further assumptions are made, that greater responding to the blank key vs. the key containing the "training" line is sufficient to produce an incremental gradient. Since incremental gradients were not obtained from two of four birds that showed differential responding during multiple VI 1-min VI 5-min training, Hearst et al.'s analysis was not supported (also see Richards \& Hittesdorf, 1976; Richards \& Marcattilio, 1978). Moreover, Farthing (1975) has demonstrated that pigeons do not merely attend to the edge of a key containing a row of dots and has suggested that it is reasonable "to continue to assume a functional orthogonality between line presence vs. line absence [p. 188]." Thus, the incremental gradients obtained in the present study seem to be valid indices of inhibitory stimulus control.

\section{REFERENCES}

Couch, J. V. Behavioral contrast and inhibitory stimulus control. Animal Learning \& Behavior, 1975, 3, 347-358.

Farthing, G. W. Stimulus control by dot position in pigeons. Bulletin of the Psychonomic Society, 1975, 6, 185-188.

Hearst, E., Besley, S., \& Farthing, G. W. Inhibition and the stimulus control of operant behavior. Journal of the Experimental Analysis of Behavior, 1970, 14, 373-409.

Honig, W. K., Boneau, C. A., Burstein, K. R., \& Pennypacker, H. S. Positive and negative generalization gradients obtained after equivalent training conditions. Journal of Comparative and Physiological Psychology, 1963, 56, 111-116.

JenKINS, H. M. Generalization gradients and the concept of inhibition. In D. I. Mostofsky (Ed.), Stimulus generalization. Stanford: Stanford University Press, 1965. Pp. 55-61.

RichaRDS, R. W. Stimulus generalization and delay of reinforcement during one component of a multiple schedule. Journal of the Experimental Analysis of Behavior, 1973, 19, 303-309.

RICHARDS, R. W. Inhibitory stimulus control and the magnitude of delayed reinforcement. Journal of the Experimental Analysis of Behavior, 1974, 21, 501-509.

RichaRds, R. W., \& HitTESDORF, W. M. Reinforcement delay: A parametric study of effects within a multiple schedule. Bulletin of the Psychonomic Society, 1976, 7, 303-305.

Richards, R. W., \& Marcattilio, A. J. Stimulus control and delayed reinforcement. Learning and Motivation, 1978, 9, 54-68.

Rilling, M. Stimulus control and inhibitory processes. In W. K. Honig \& J. E. R. Staddon (Eds.), Handbook of operant behavior. Englewood Cliffs, N.J: Frentice-Hall, 1977. Pp. 432.480.

TERRACE. H. S. By-products of discrimination learning. In G. H. Bower \& J. T. Spence (Eds.), Learning and motivation, V. New York: Academic Press, 1972. Pp. 195-265.

WEISMAN, R. G. Some determinants of in hibitory stimulus control. Journal of the Experimental Analysis of Behavior, 1969, 12. 443-450.

WEISMAN, R. G. Factors influencing inhibitory stimulus control: Differential reinforcement of other behavior during discrimination training. Journal of the Experimental Analysis of Behavior, $1970,14,87-91$.

Weisman, R. G., \& RAmsden, M. Discrimination of a responseindependent component in a multiple schedule. Journal of the Experimental A nalysis of Behavior, 1973, 19, 55-64.

YARCZOWER, M. Behavioral contrast and inhibitive stimulus control. Psychonomic Science, 1970, 18, 1-3.

(Received for publication December 20, 1977; revision accepted March 13, 1978.) 